
به منظور تحليل فراوانى منطقهاى سيلى سيلاب

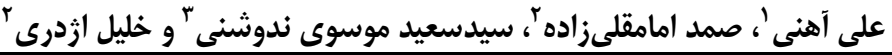

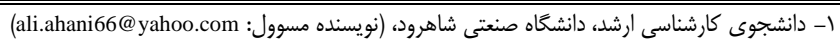

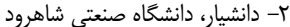

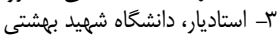

تاريخ دريافت:

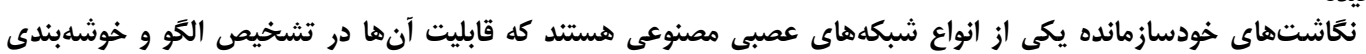

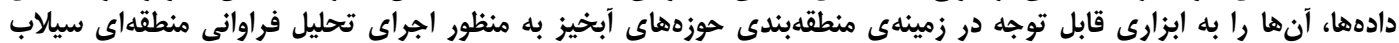

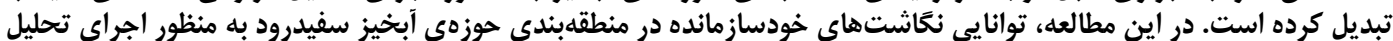

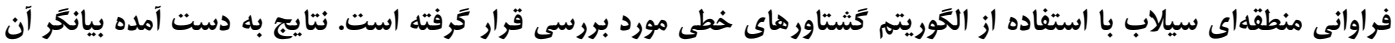

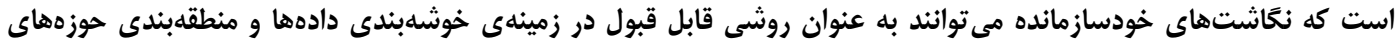

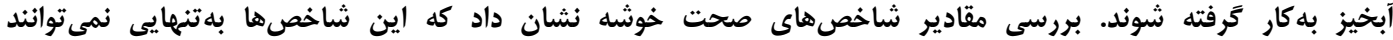

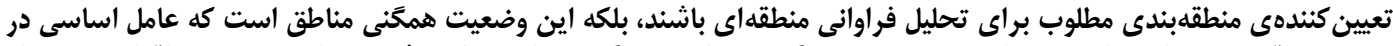

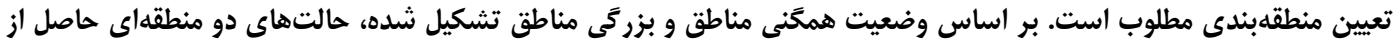

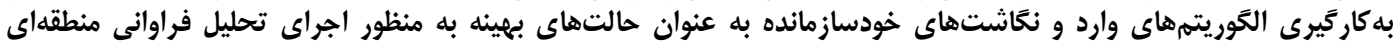

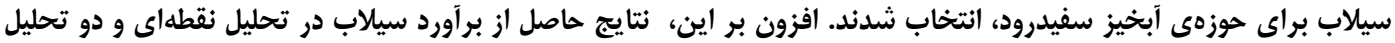

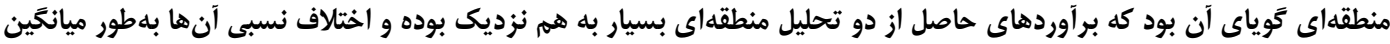

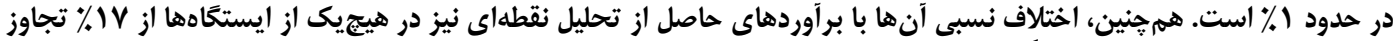

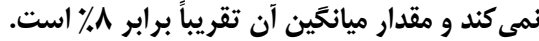

وازههاى كليدى: نكاشت خودسازمانده، منطقهبندى، خوشهبندى، تَشتاورهاى خطى

تقسيمبندى هستند. همجنين به منظور بهره

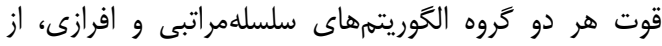

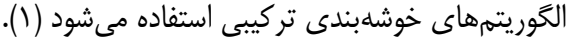

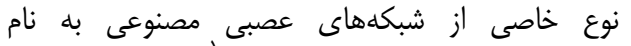

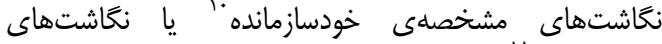

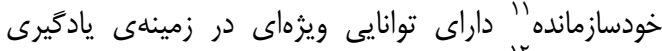

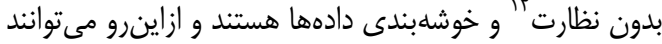

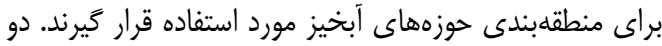

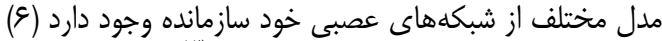

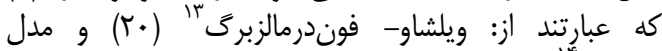

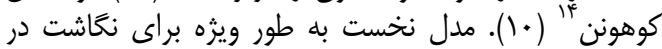

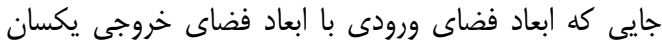

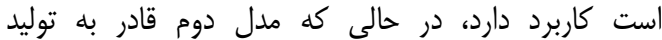

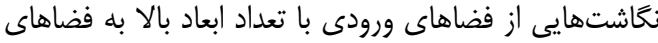

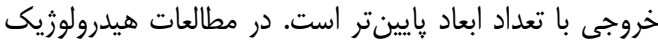

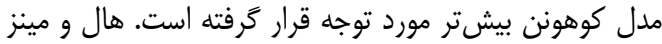

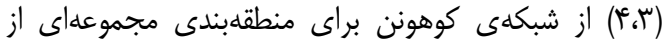

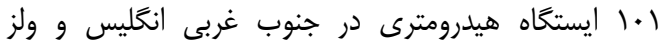

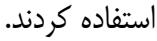

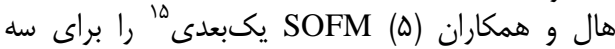

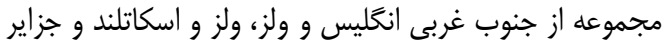

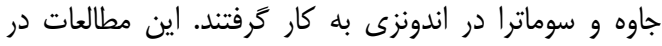

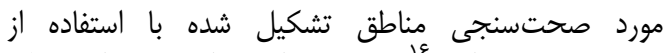

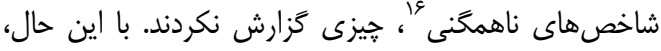

مقدمه

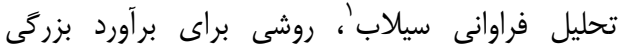

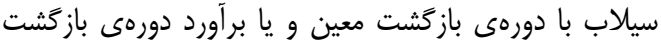

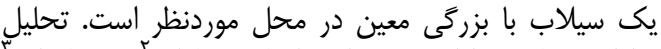

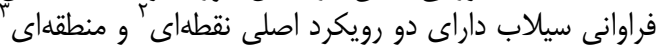
است.

در تحليل فراوانى منطقهاى سيلاب با گردآورى حوزهها

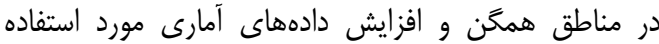

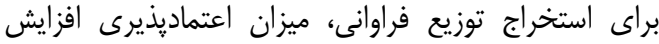

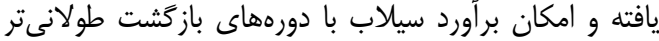

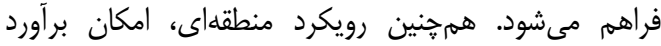

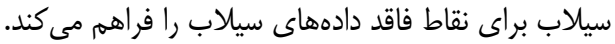
يس از بررسى كيفيت و صحت دادهها، نخستين مرحلهي

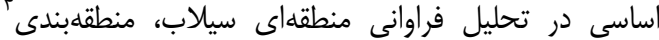

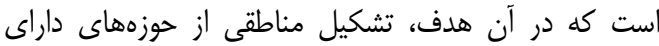

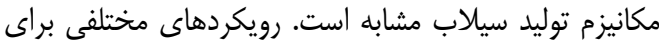

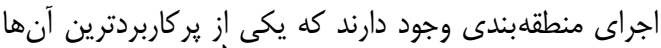

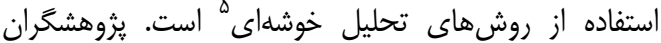

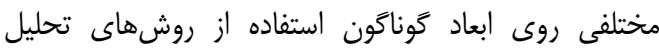
خوشهاى براى اجراى منطقلهبندى در تحليل فرای فراوانى منطقائهاي

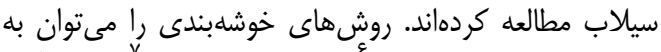

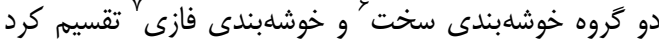

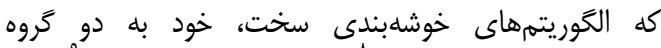

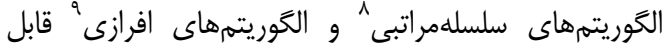

1- Flood Frequency Analysis

4- Regionalization

7- Fuzzy Clustering

10- Self-Organizing Feature Maps (SOFM)

13- Willshaw - Von Der Malsburg

16- Heterogeneity Measures
2- At-Site

5- Cluster Analysis

8- Hierarchical Algorithms

11- Self-Organizing Maps (SOM)

14- Kohonen
3- Regional

6- Hard Clustering

9- Partitional Algorithms

12- Unsupervised Learning

15-1-D 
خوشهاى غيرخطى شامل SOFM را براى تشكيل خوشهاهاى

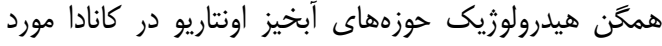

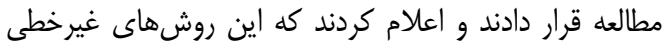

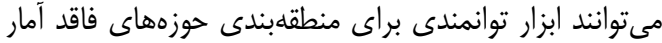
باشند.

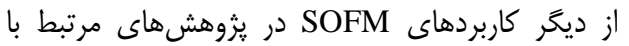

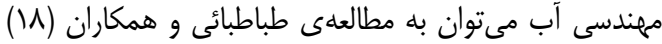

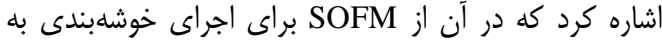
منظور برآورد غلظت رسوب معلق روزان انه ايستخاه هيدرومترى

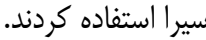

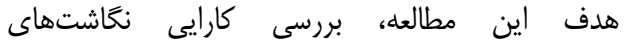

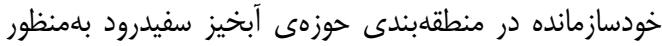

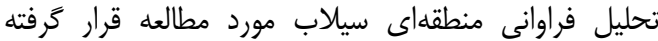

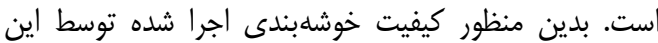

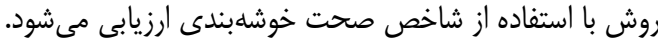

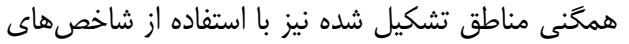

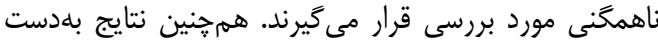

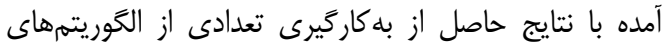

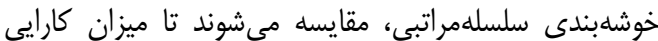
اين روش به نسبت روشهاى معمول سنجيده شود.

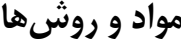
معرفى حوزهى آبخيز سفيدرود

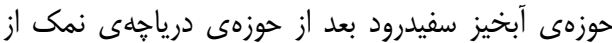

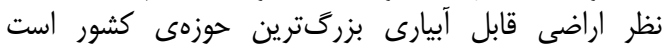

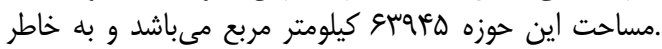

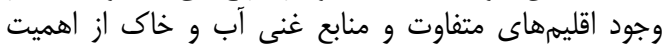

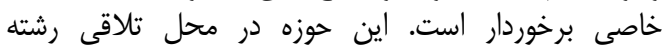

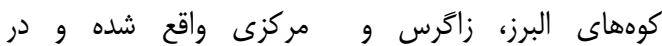

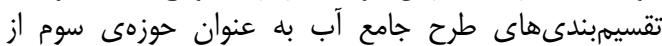

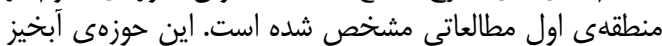

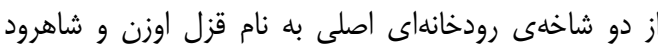

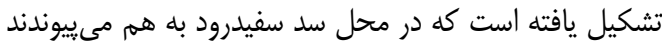

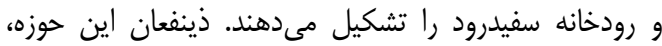

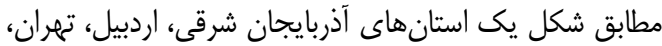

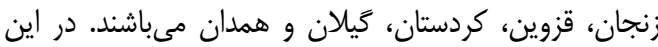

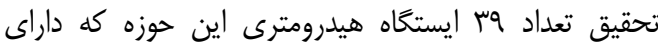

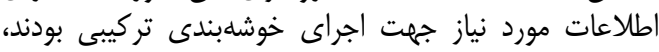

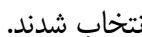

جينخيى و هال (^) شاخص هاى ناهمكنى هاسكينخ و واليس

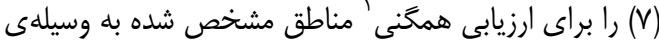

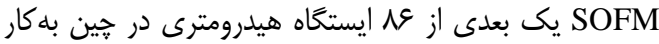
كرفتند.

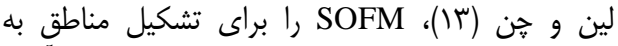

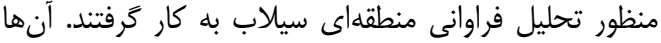

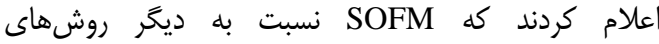
خوشابندى توانايى بالاترى در تشكيل مناطق همكَن دارئ دارند و

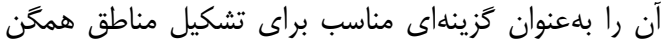

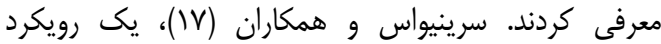

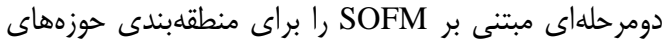

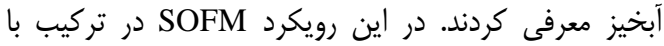

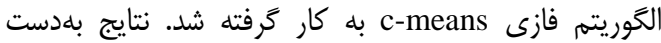

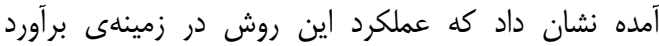

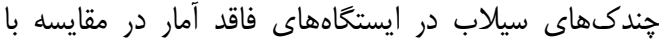

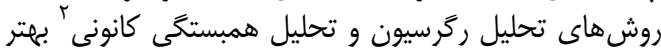

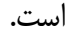

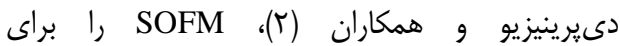

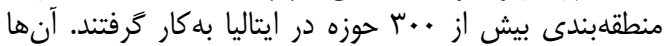

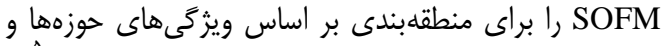

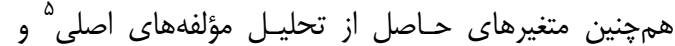

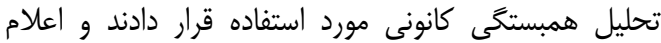

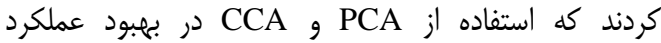

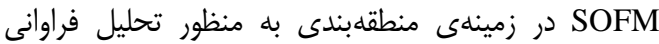

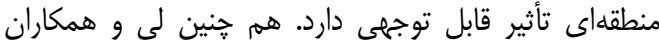

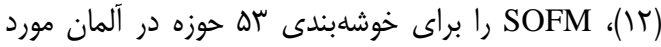

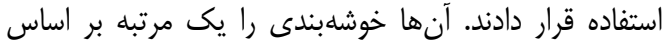

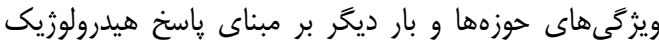

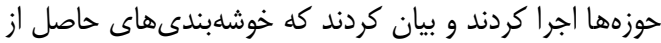

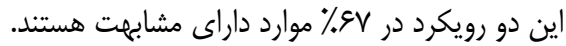

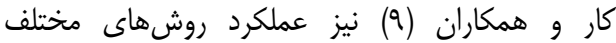

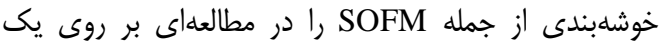

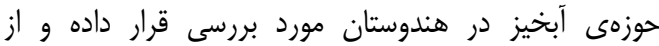
مقايسهى نتايج آنها براى تعيين تعداد بهينهى مردي مناطق

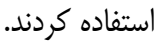

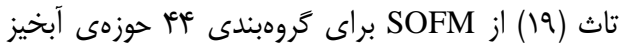

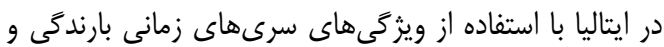

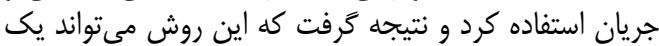

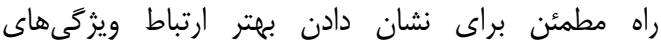
هيدرولوزيك و اقليمى حوزهها باشد.

رضوى و كوليبالى (ه)، كاربرد تكنيكهاى تحليل 


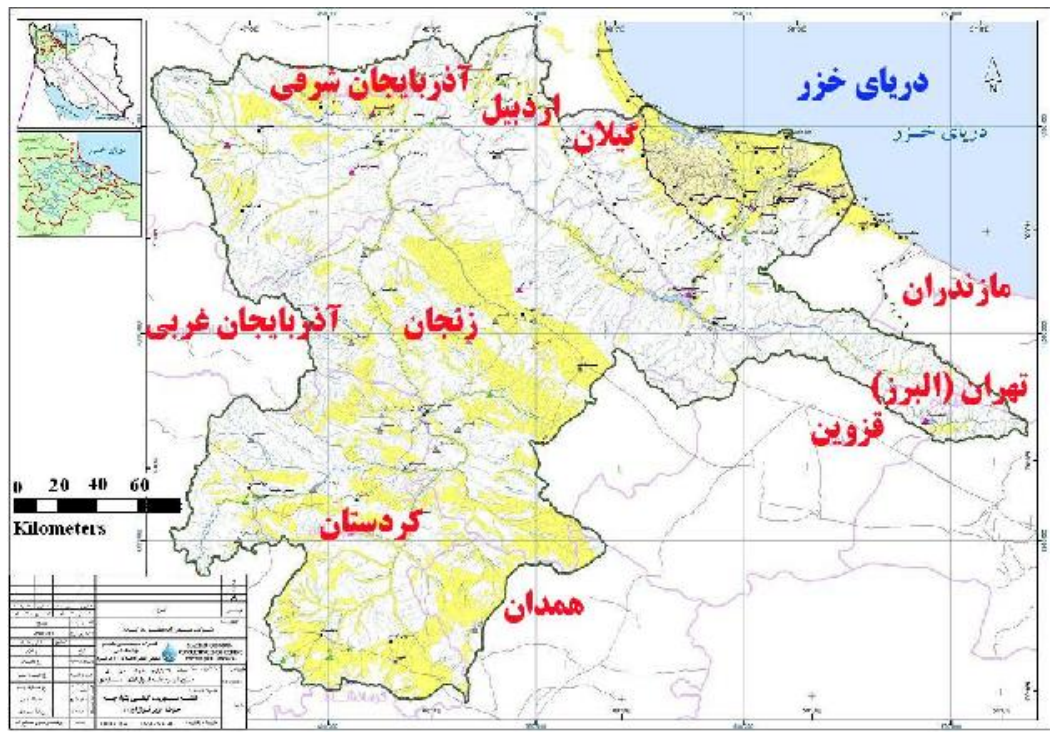

شكل ا- موقعيت جغرافيايى حوزمى آبخيز سفيدرود (قزل اوزن) (شركت مهندسى مشاور مهاب قدس)

Figure 1. Geographical location of Sefidroud (Ghezel-Owzan) basin (Mahab Ghodss Consulting Engineering Company)

ايستخاهها با لكاريته آنها جايخزين شد.

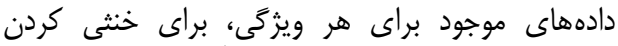

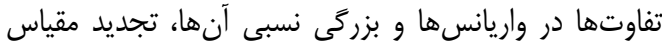

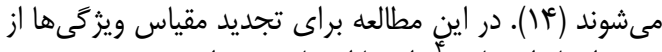
روش استانداردسازى دادي دادها استفاده شده است اكر

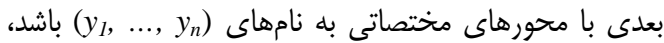
كه بعا

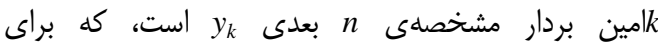
استانداردسازى دادهها از رابطه يك استفاده مى شود: $x_{i k}=\frac{y_{i k}-\mu_{i k}}{\sigma_{i}}$

\section{for $1 \leq i \leq n, 1 \leq k \leq N$}

كه در آن xik : نشاندهنده مقدار تجديد مقياس شده

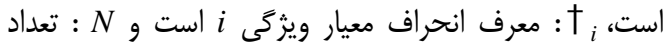

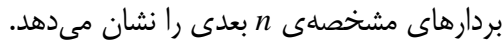

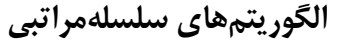

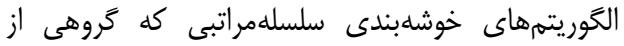

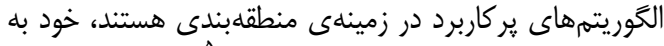

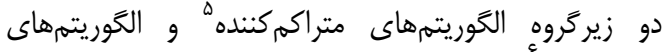

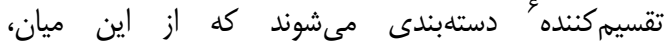

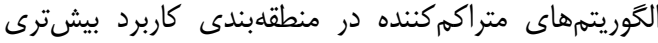
يافتهاند.

براى مجموعهاى از N N بردار مشخصله، روشهاى بإي

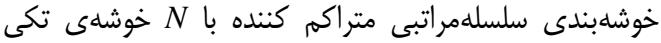

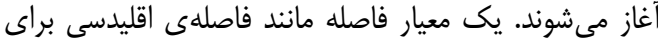

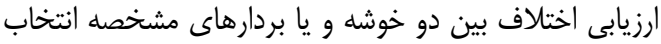

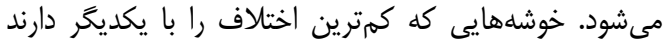

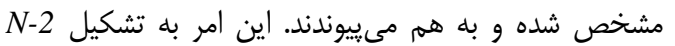

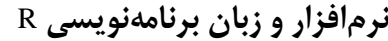

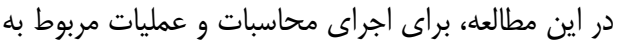

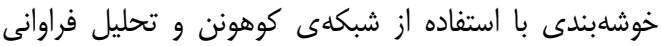

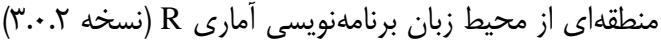

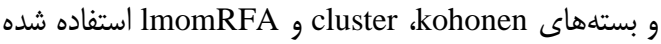

غربال كردن دادهها

يبش از تشكيل مناطق، شاخص ناجورى '

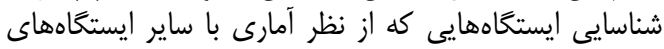

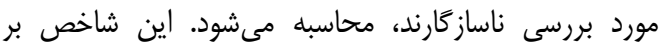

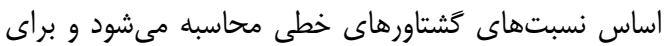

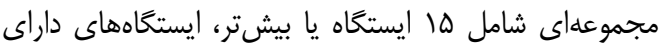

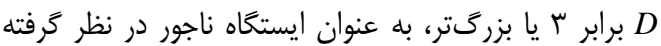

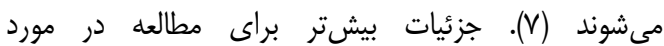

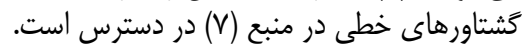

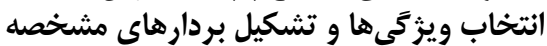

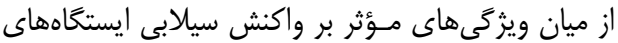

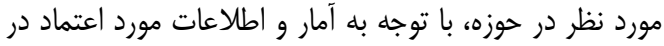

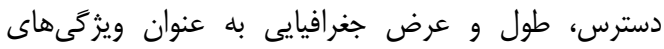

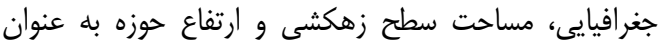

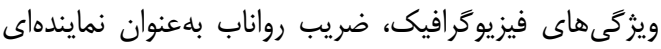

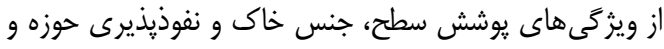

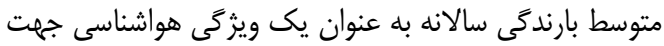

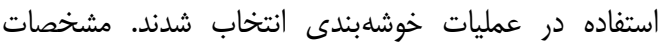

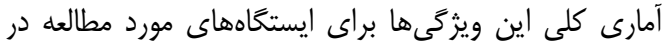
جدول يك ارائه شده است.

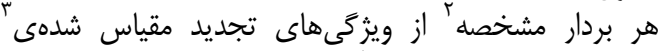

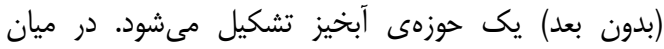

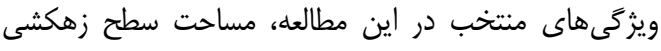

\begin{tabular}{lll}
\hline 1- discordancy measure & 2- Feature Vector & 3- Rescaled \\
4- Standardization & 5- Agglomerative & 6- Divisive
\end{tabular}


تعداد خوشههاى موجود يس از n مرتبه ادغام برابر n-N است
خوشهى تكى و يكى خوشه شامل دو بردار مشخصاه منجر

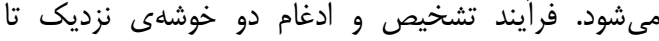

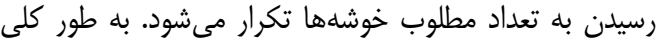

Table 1. Statistical characteristics of selected attributes of the interested stations

جدول ا- مشخصات آمارى ويثخى هاى بركزيدهى ايستخاههاى مورد مطالعه

انحراف معيار

$\cdot / V^{2}$

$|r \cdot F / \Delta|$

rTH/QT

.

\begin{tabular}{|c|c|}
\hline ميانغين & ويزگ \\
\hline$\hat{F N} / \mathrm{V}$. & طول جغرافيايى (dd) \\
\hline 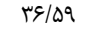 & عرض جغرافيايى (dd) \\
\hline$\Delta \wedge I V / \Delta I$ & سطح زهكشى (km²) \\
\hline 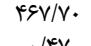 & متوسط بارندگى سالانه (mm) \\
\hline.$/ 4 \mathrm{~V}$ & ضريب رواناب \\
\hline
\end{tabular}

باشد. براى يك SOFM يك بعدى، هال و مينز (†) مقدار

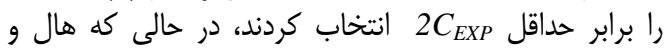
همكاران (ه) مقدار آن را حداقل برابر مابر

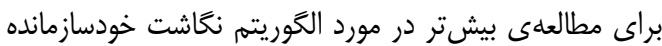
كوهونن مىتوان به منبع (و) مراجعه كرد درد در اين مطالعه، شبكهان بهاى كوهونن خطى مورد برد بررسى قرار كرفته|ند.

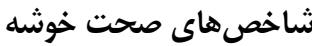

خوشههاى تشكيل شده به به صورت بصرى و و با استفاده از

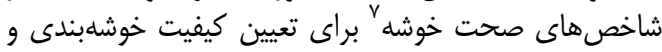

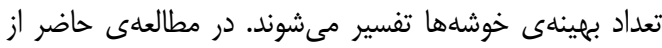

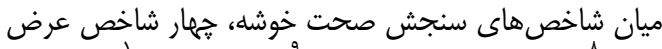

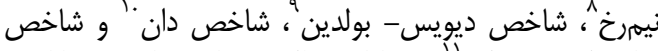

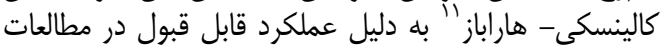

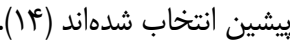

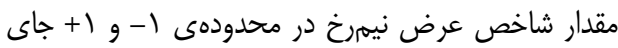

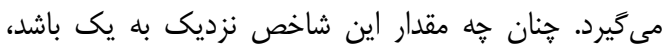

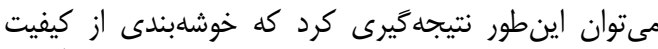

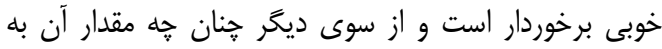

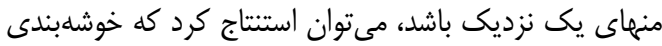

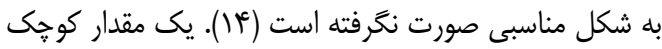

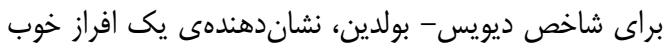

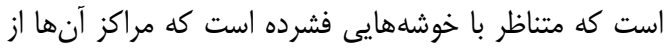

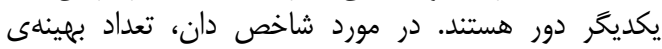

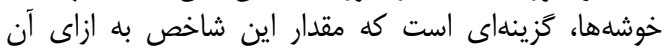
بيشينه مىشود. در مورد شاخص كالينسكى - هاراباز نيز، مقدار بيشينهى

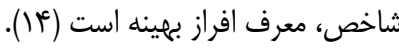

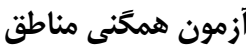

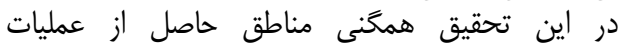

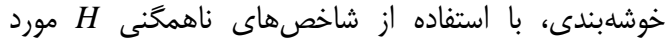

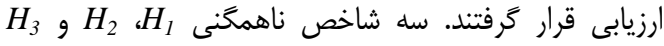

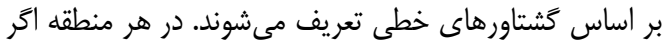
نا نسبتاً ناهمكن و اكر

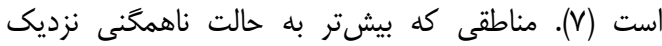

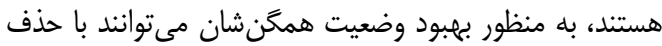
يك يا جند ايستخاه كه تأثير بيشترى در افزايش ناهمخ تهنى

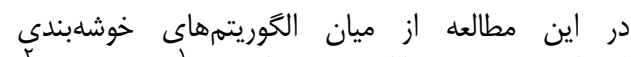

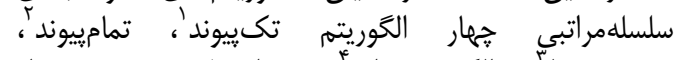

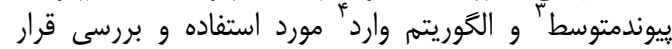

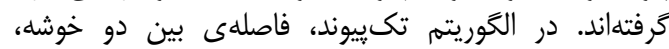

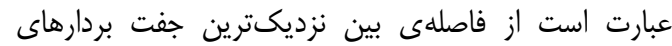

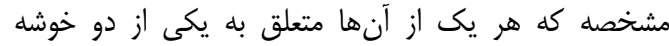

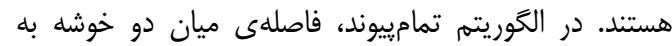

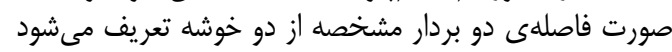

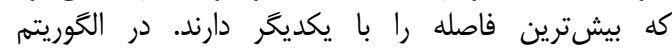

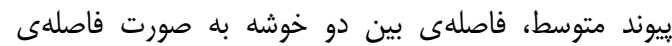

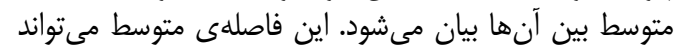

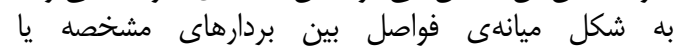
ميانگينهاى وزنى يا غيروزنى فواصل بردارهاى مشخصلى مشارى

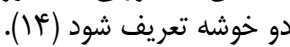

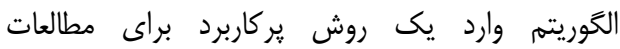

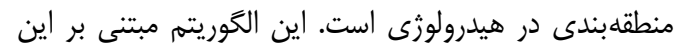

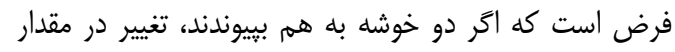

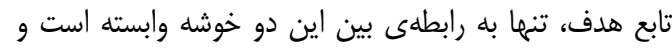

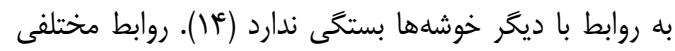

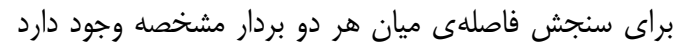
كه در اين مطالعه از تعريف فاصلهى اقليدسى استفاده شده

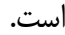

نكاشتهاى خودسازمانده كوهونن كوهونن داراى يك لايهى ورودى و و يك لايهى

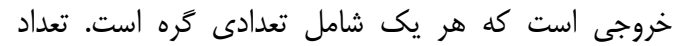

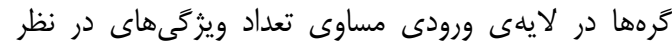

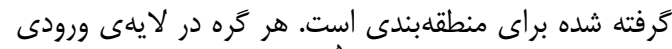

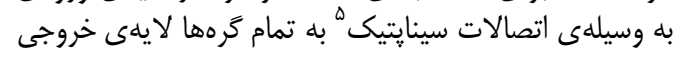

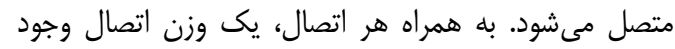
دارد (申) تعداد كرهها در لايهى ورودى SOFM برابر ابعاد بردار

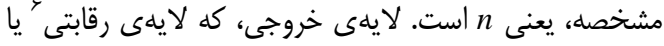
لايهى كوهونن نيز خِوانده مى شئهد، داراى

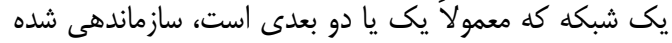

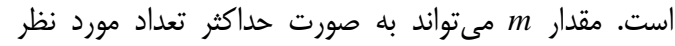

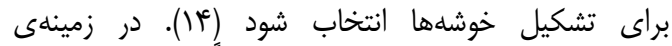

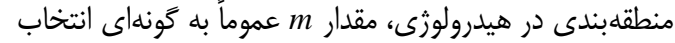
مىشود كه بزركتر از تعداد خوشههاى مورد انتظار
1- Single Linkage

4- Ward's Algorithm

7- Cluster Validity Measure

10- Dunn's Index
2- Complete Linkage

5- Synaptic

8- Silhouette Width

11- Calinski - Harabasz index
3- Average Linkage

6- Competitive Laye

9- Davies - Bouldin Index 
برآورد سيلاب در تحليل فراوانى منطقهاى تا زمانى قابل

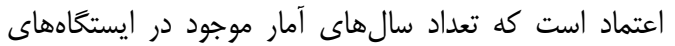

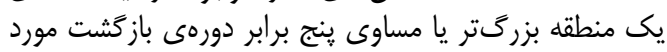

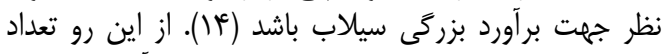

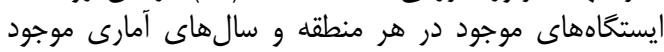

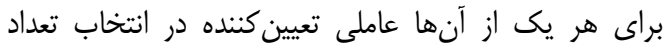

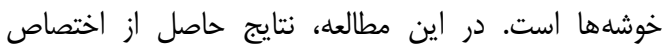

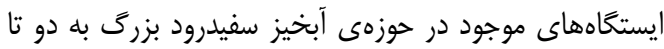

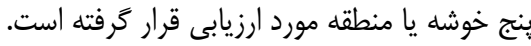

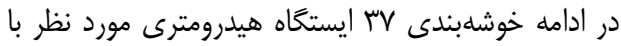

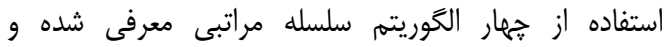

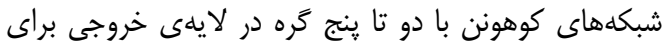

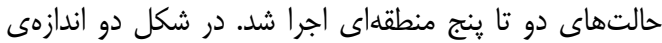

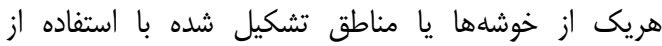

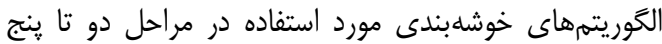

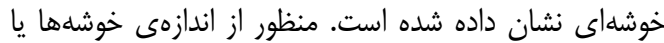

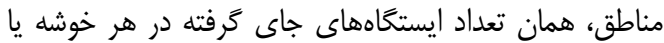

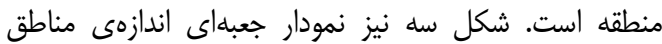

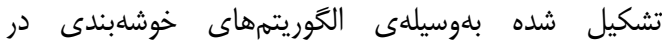

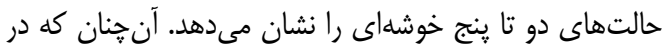

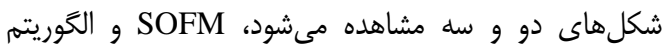

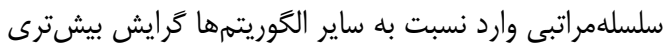
به تشكيل خوشههايى با تعداد اعضاى نزديك بله به هم دئ دارند.

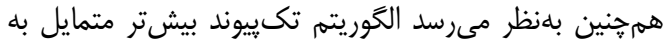

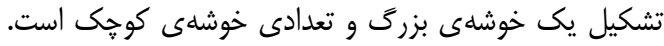

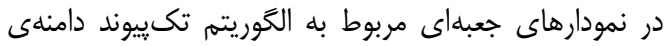

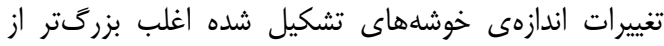

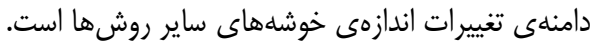

دارند يا جا به جايى محدود برخى ايستخاهها بين خوشهها و يا

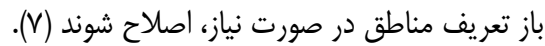

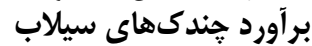

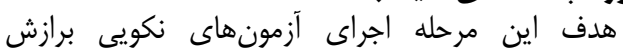

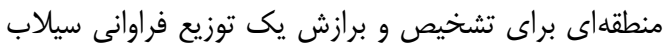

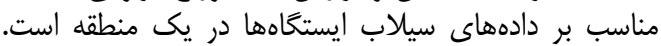

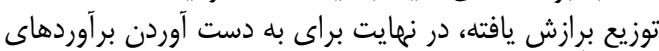

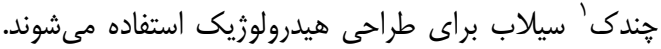

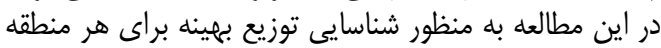

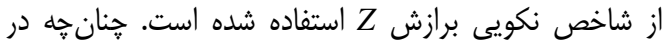
يك منطقه براى توزيعى خاص لئ (DIST)،

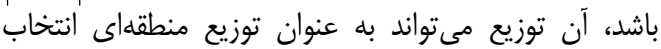

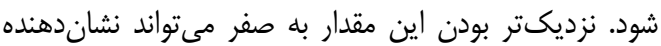

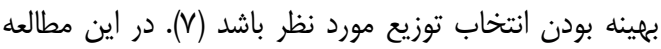

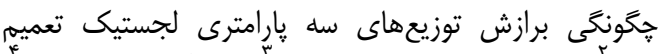

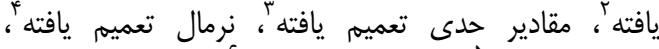

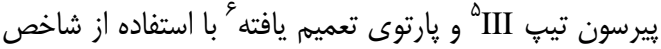
نكويى برازش Z

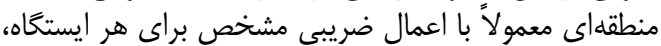

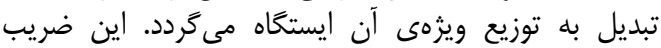
مىتواند متوسط دبى حداكثر لحظهاى هر ايستخاه باشد.

\section{نتايج و بحث}

ييش از بررسى وضعيت همخَنى مناطق شاخص ناخس ناجورى

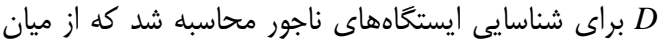

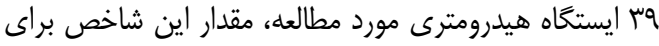
دو ايستخاه از مقدار مجاز

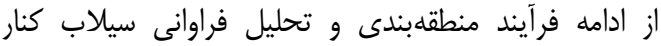

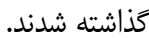
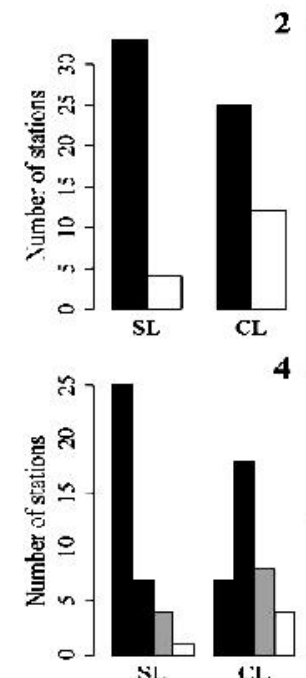

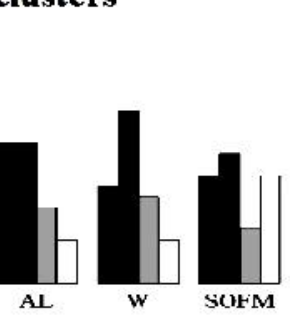

2 clusters
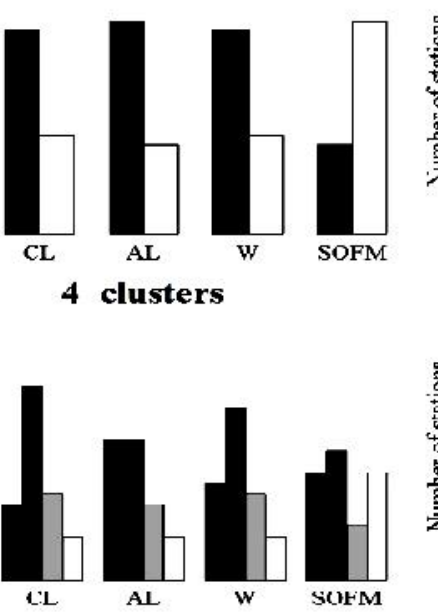
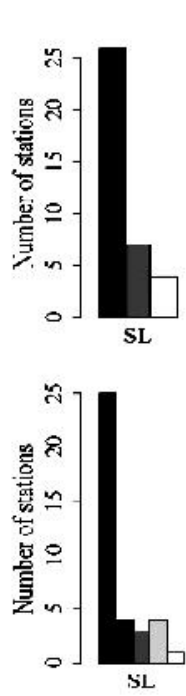

\section{3 clusters}
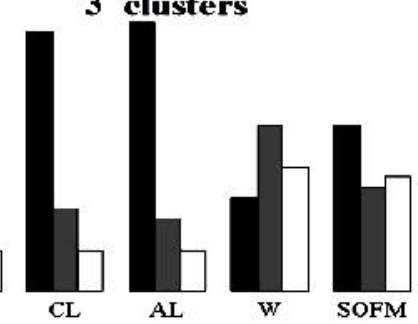

5 clusters

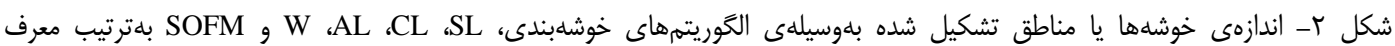

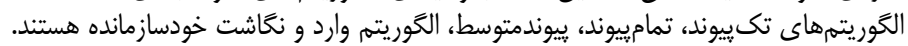

Figure 2. Sizes of clusters or regions formed by clustering algorithms; SL, CL, AL, W and SOFM denote Single Linkage, Complete Linkage, Average Linkage, Ward's algorithm and Self-Organizing Feature Map, respectively

1- Quantile 2- Generalized Logistic (GLO) $\quad$ 3- Generalized Extreme Values (GEV)



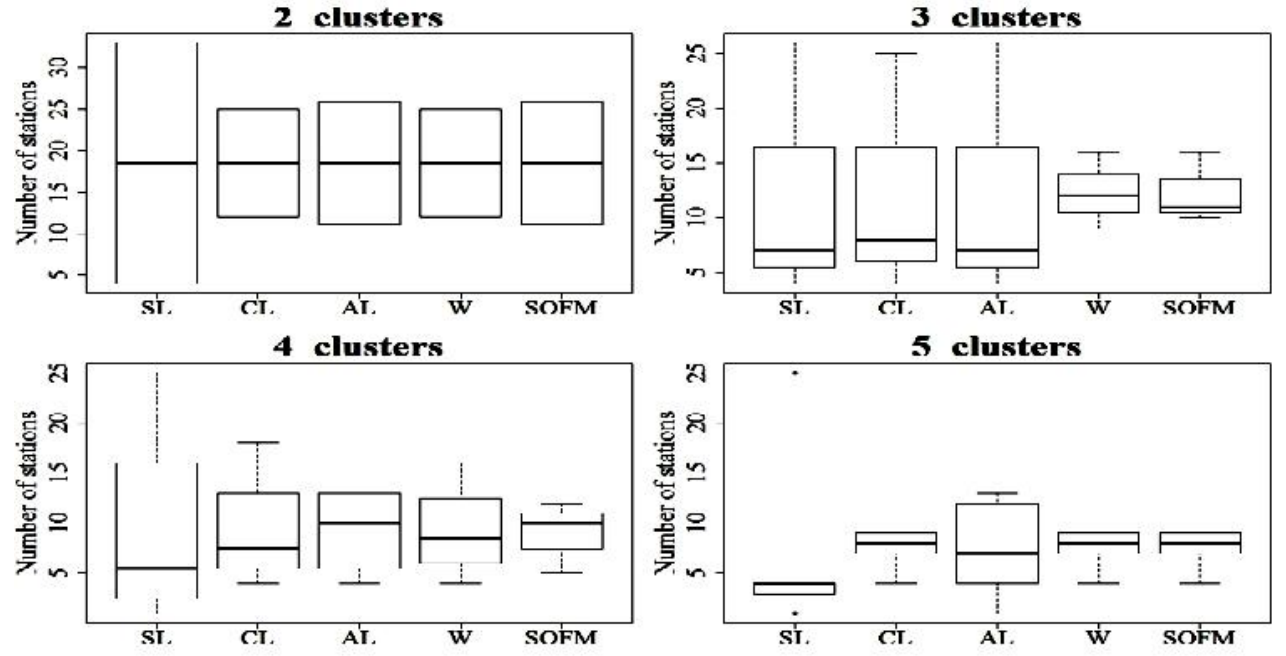

شكل ب- نمودار جعبهاى اندازهى مناطق تشكيل شده بلوسيلهى الخوريتمهاى خوشهبندى .

Figure 3. Boxplot for sizes of regions formed by clustering algorithms

لاريتم مساحت بزرى هستند. اما گره دوم داراى وزن مقادير

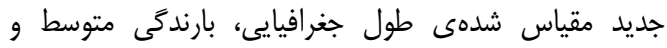

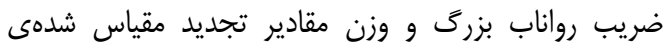

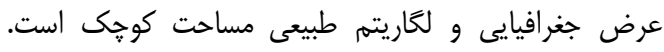

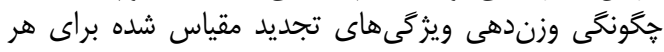

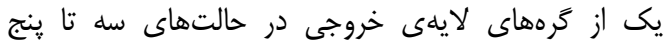

منطقهاى نيز بهصورت مشابه قابل بررسى و تفسير است درى

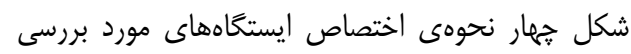

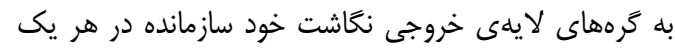

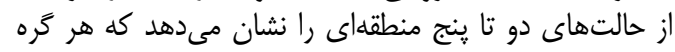

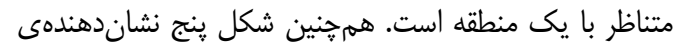

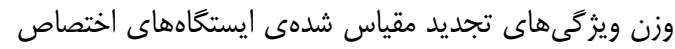

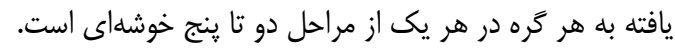

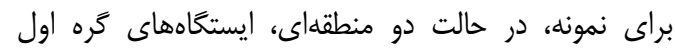

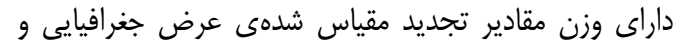
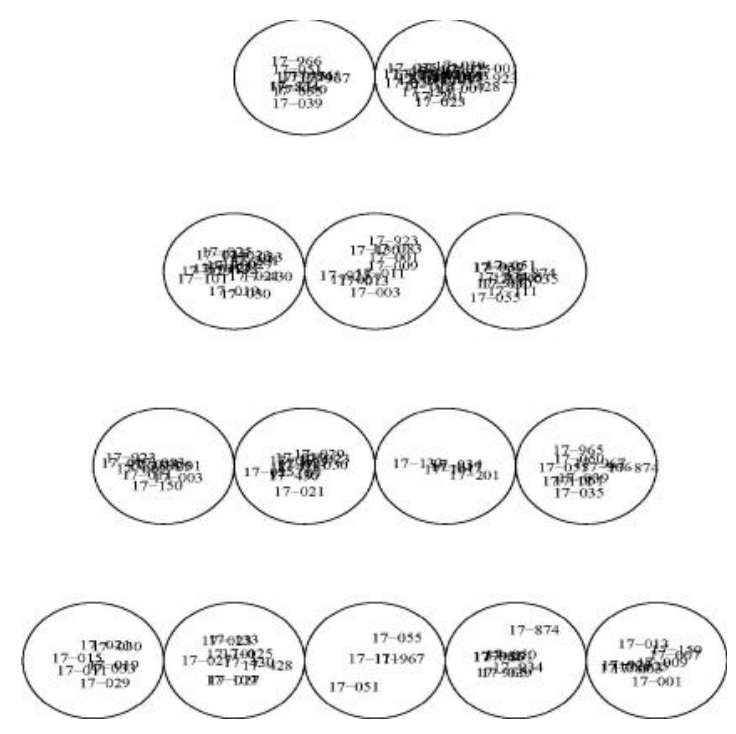

شكل זٔ- اختصاص ايستخاهها به كرههاى لايهى خروجى نگاشت خودسازمانده. شمارهها معرف كد ايستخاهها هستند. (عدد IV كد حوزه است) Figure 4. Station assignment to output-layer of SOFM. The numbers represent station codes (The number 17 denotes the basin code.) 


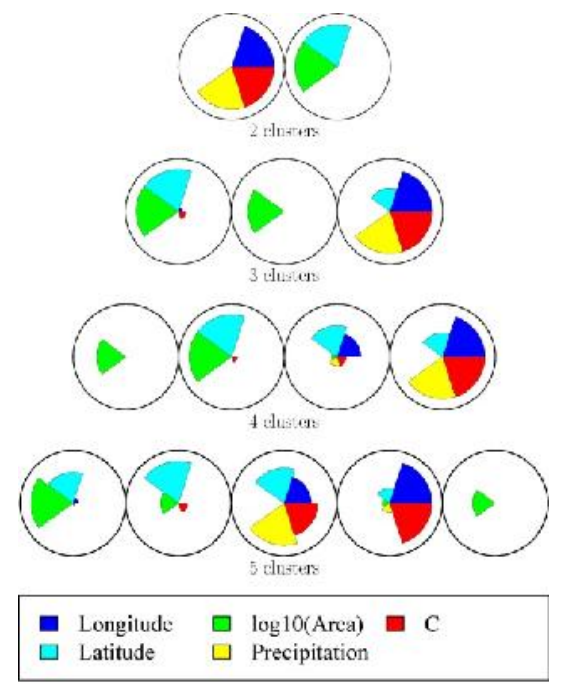

شكل ه- وزن ويثَى هاى تجديد مقياس شده در گرهاى لايهى خروجى

Figure 5. Weights of rescaled attributes at output-layer nodes

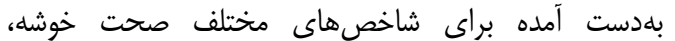

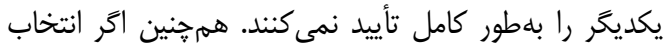

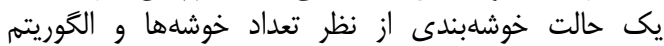

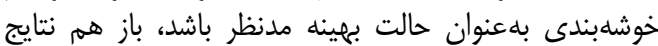

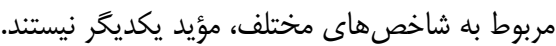

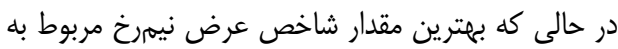

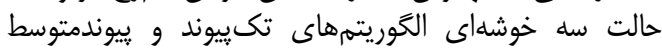

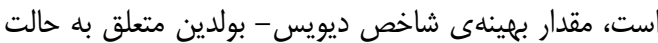

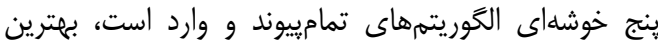

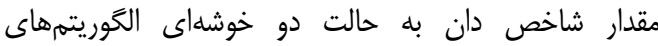

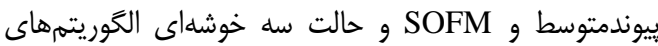

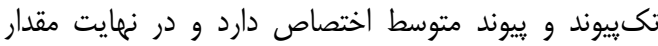

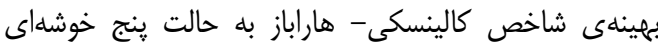

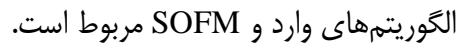

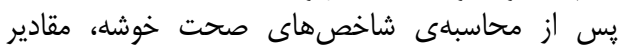
شاخصهاى ناهمكنى

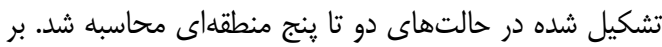

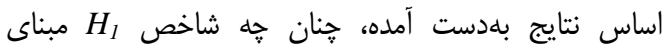

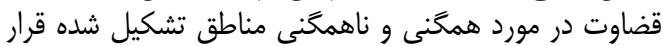

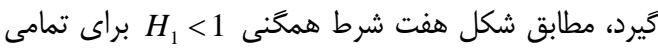
مناطق تشكيل شده برقرار است و تنها منطقئى اونى اول تشكيل

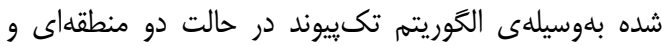

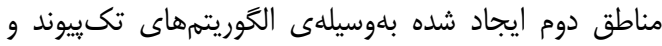

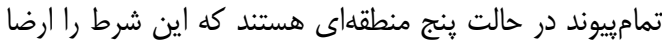

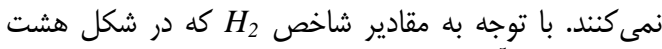

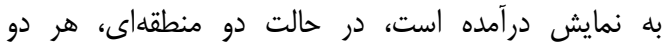

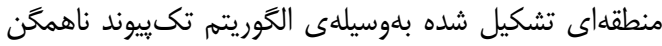

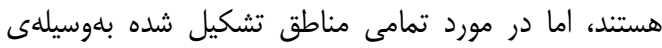

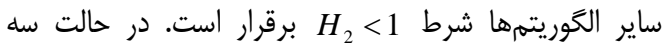
منطقهاى، تنها در مورد الكَوريتم وارد، شرط همخَنى براى هر درات
در ادامه مقدار جهار شاخص صحت خوشه معرفى شده

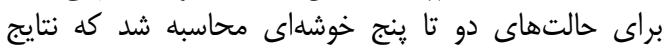

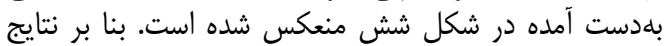

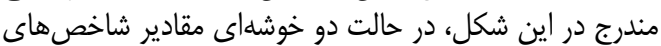

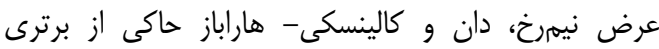

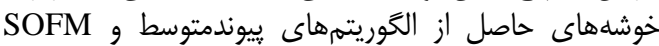
هستند، در حالى كه بر اساس الغر شاخص دين ديويس- بولدين،

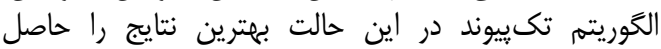

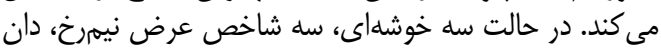

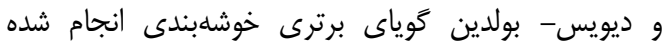

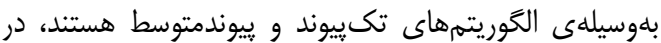

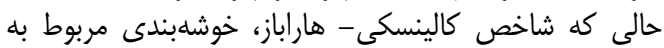

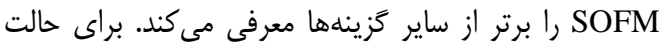

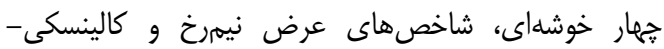

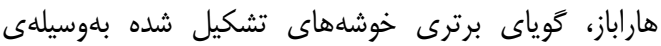

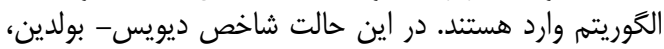

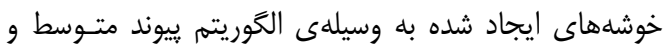

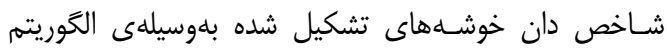

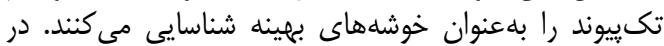

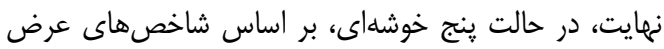

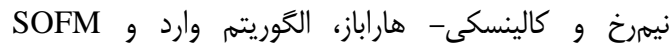

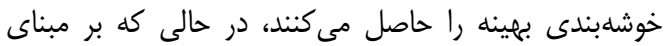

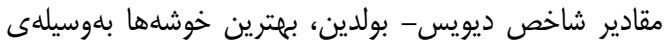

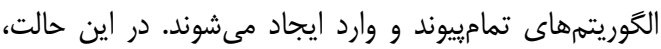

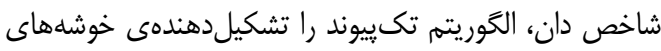
بهينه معرفى مى كندا

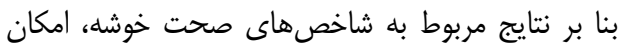

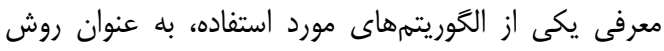

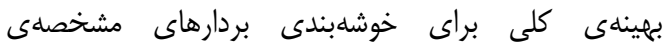
ايستخاههاى مورد مطالعه وجود ندارد. به اين معنا كه مقادير 


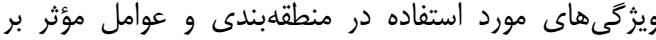

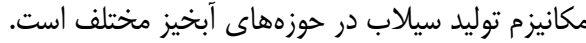

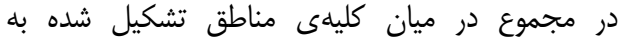

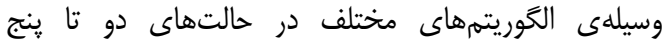

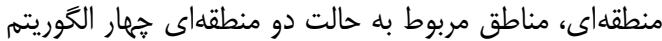

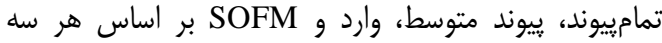

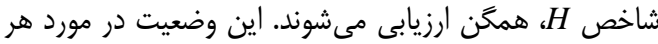

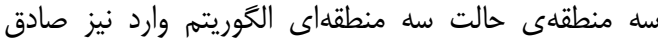

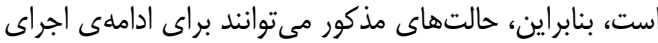

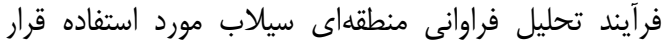

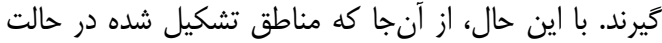

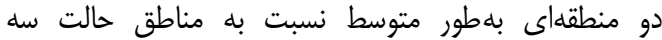

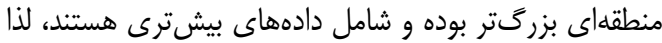

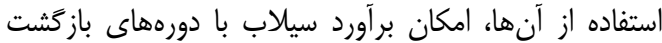

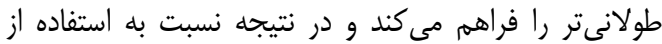

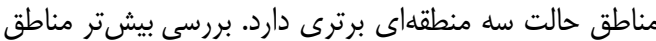

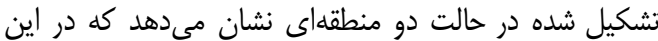

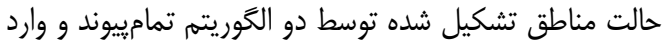

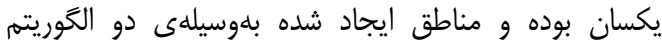

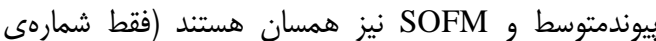

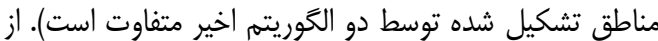

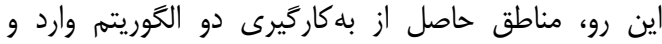

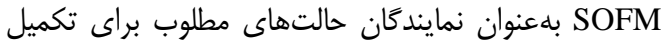

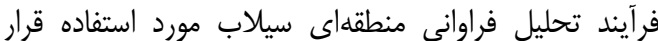

كرفتند.
سه منطقه برقرار است و در مورد ساير الكوريتمها، همواره

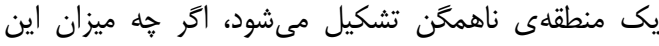

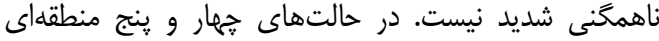

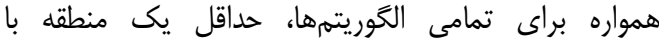
ناهمخنى جزئى ديده مى شودار

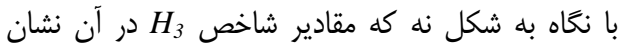

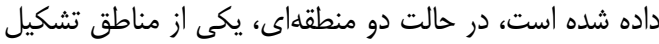

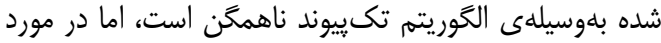
كليهى مناطق ايجاد شده توسط ساير الخوريتهمها براي 1

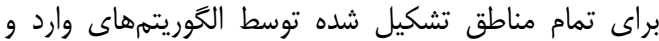

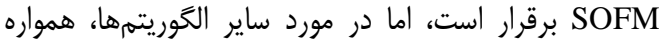

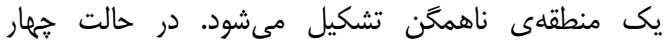

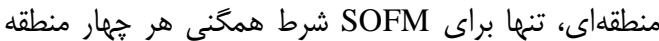

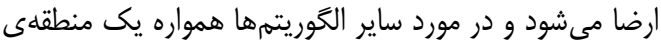

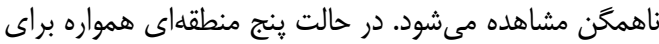

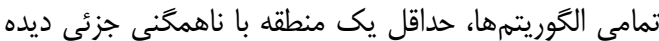
مى شود. - افي با توجه به نتايج مربوط به شاخصهاى ناهمخَى، مى كىوان

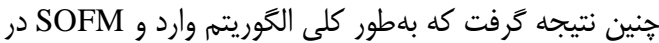

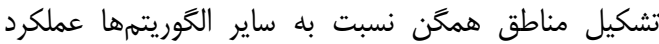

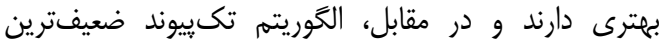

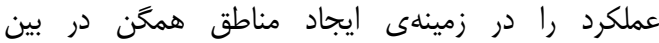

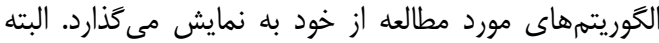

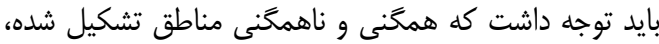

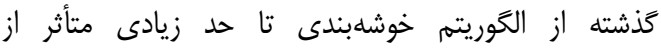
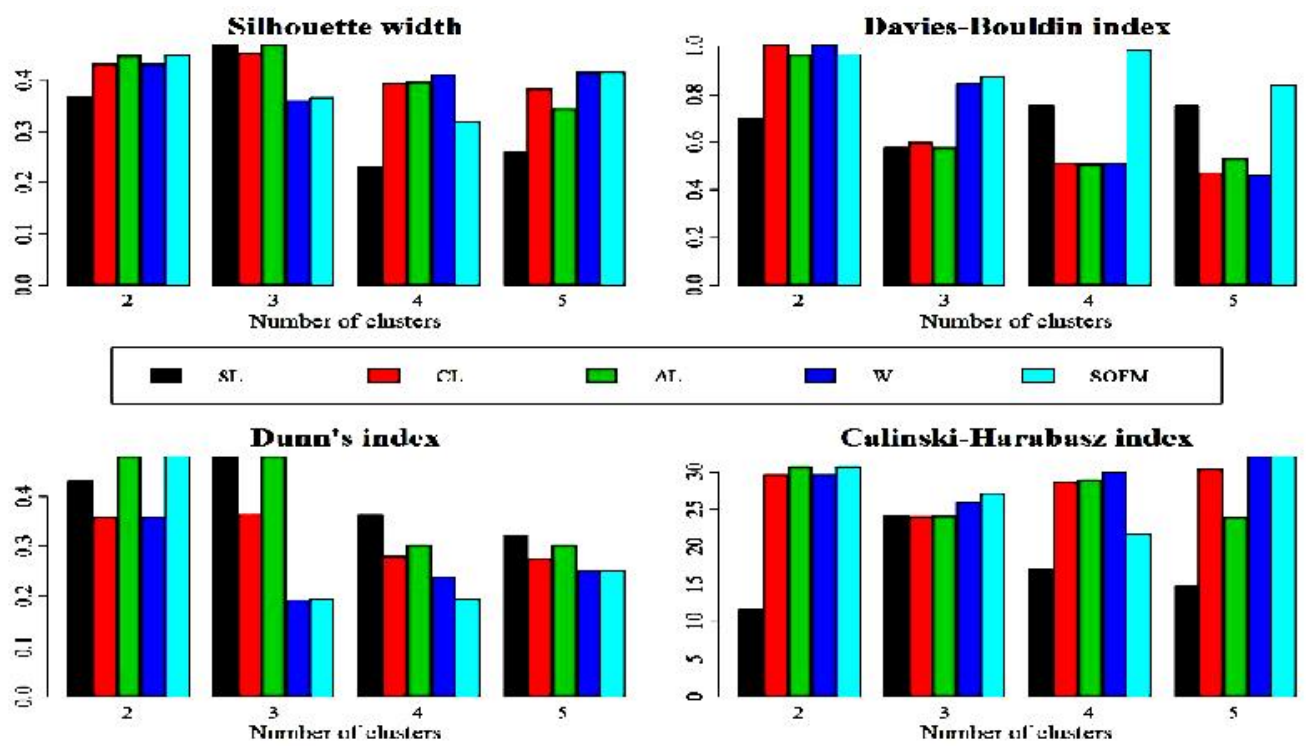

شكل צ- مقادير متوسط شاخصهاى صحت خوشه براى تعداد دو، سه، جهار و پنج خوشه

Figure 6. Average values of cluster validity measures for two, three, four and five clusters 

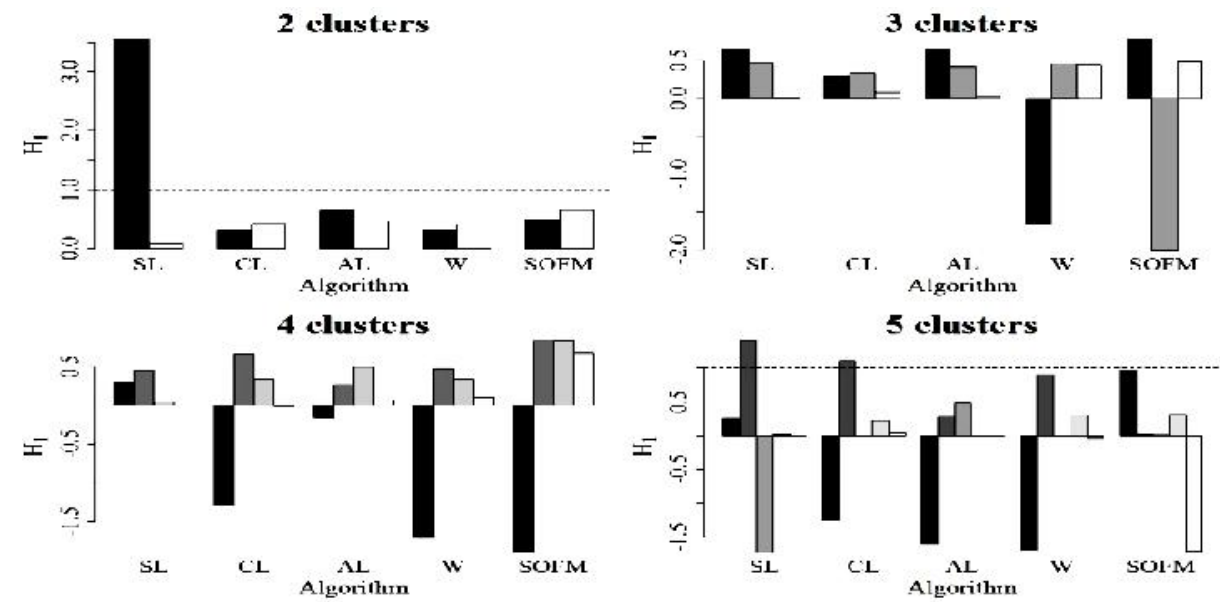

شكل V- مقدار شاخص ناهمخَى H H H براى مناطق تشكيل شده

Figure 7. The values of the heterogeneity measure $H_{l}$ for the formed region
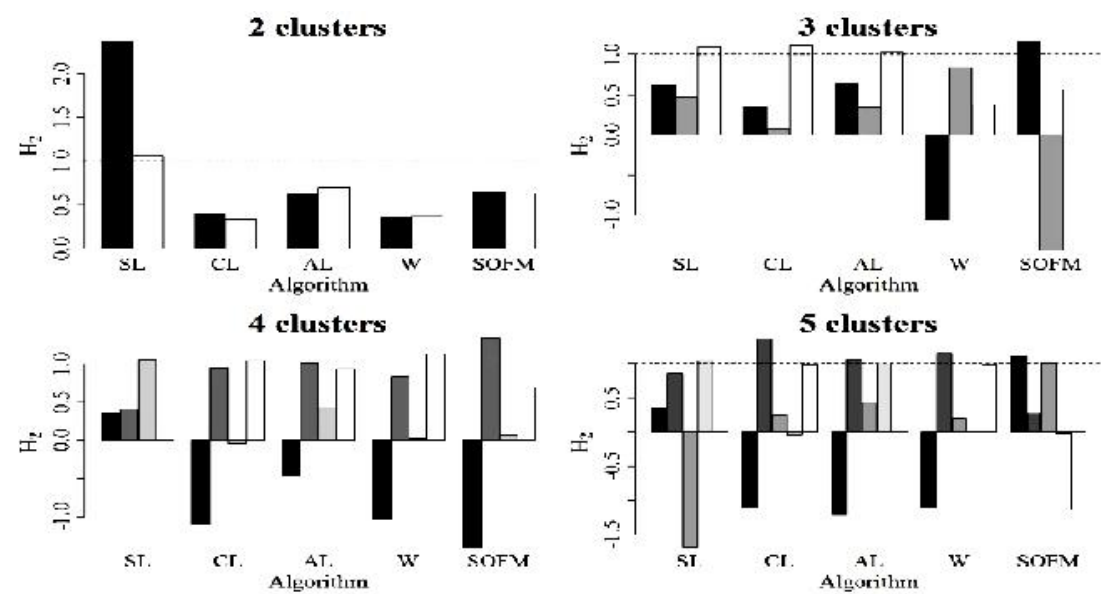

شكل ^- مقدار شاخص ناهمخنى H

Figure 8 . The values of the heterogeneity measure $H_{2}$ for the formed region
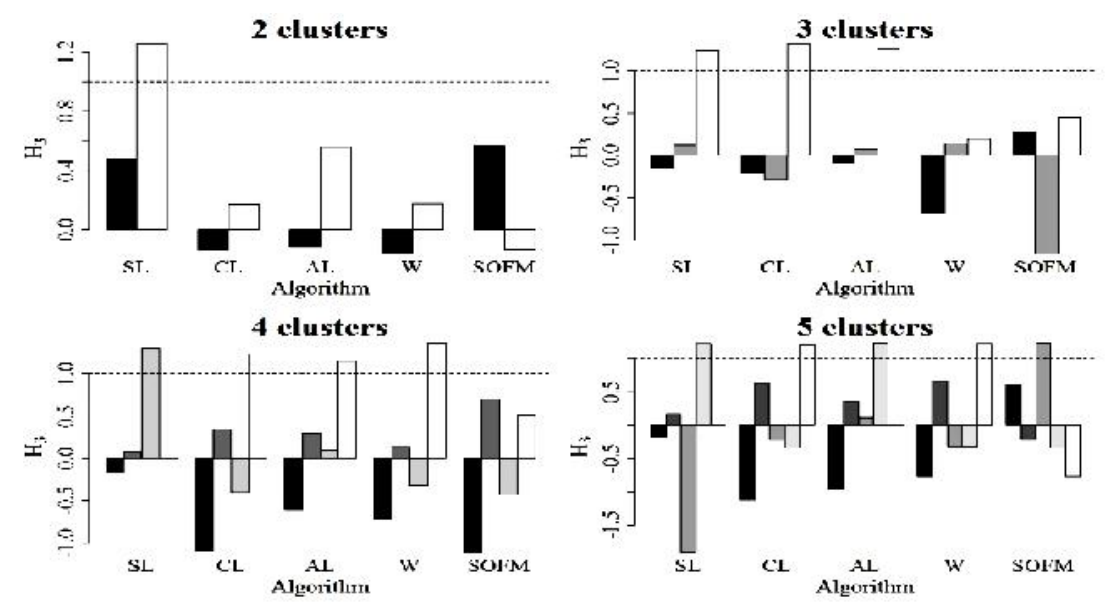

شكل 9- مقدار شاخص ناهمخنى

Figure 9. The values of the heterogeneity measure $H_{3}$ for the formed region 
اختلاف بين برآوردهاى دو تحليل منطقهاى اغلب بسيار ناجيز

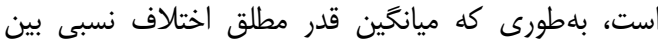

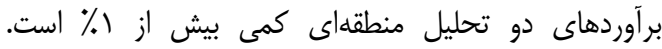

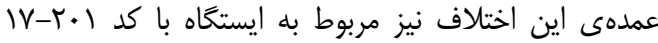

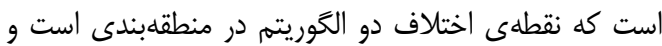
اختلاف نسبى مربوط به آن نيز در برآ آورد سيلاب در دو دو تحليل

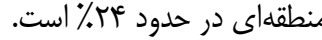

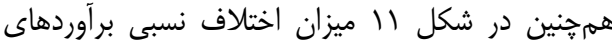

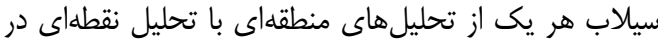

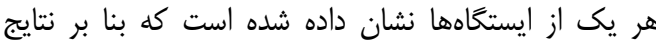

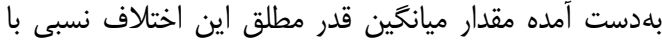

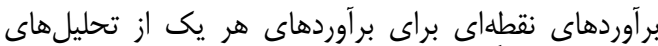

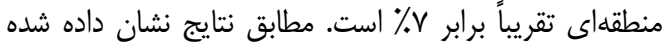

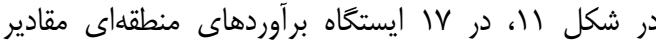

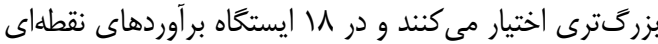

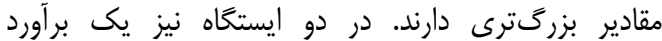

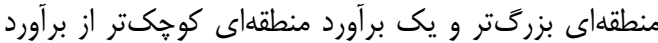

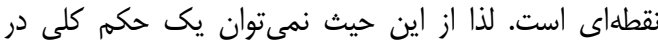

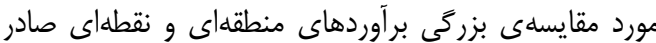

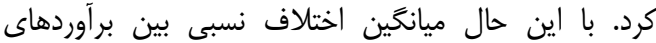

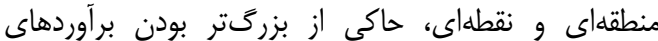

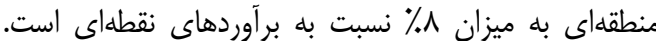

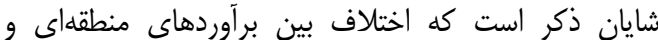

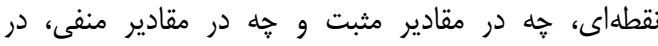

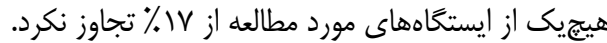

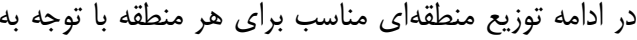

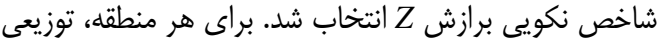

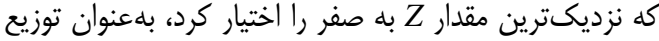

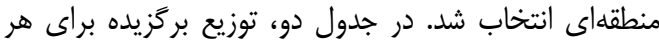

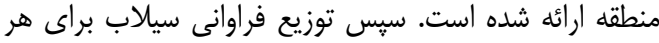

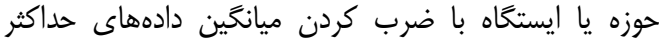

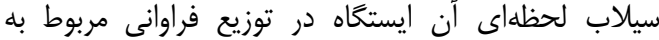

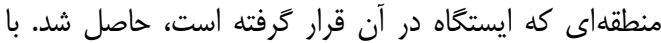

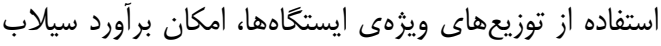

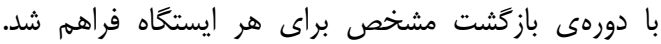

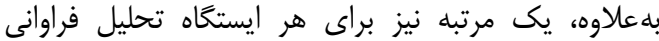

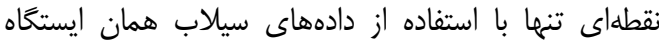

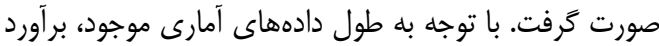

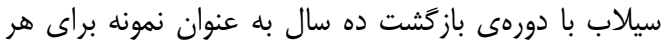

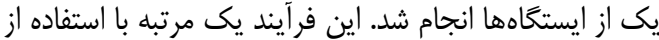

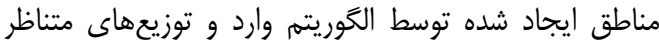

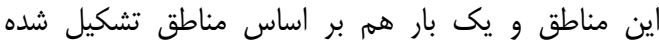

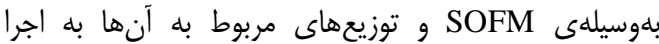

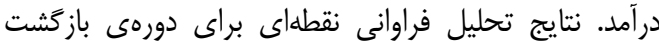

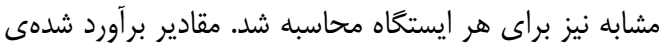

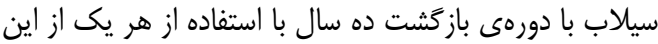

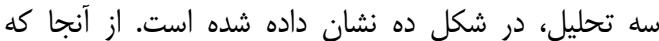

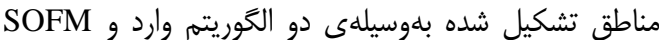

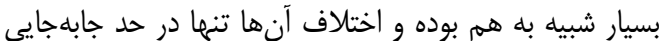
يك ايستخاه است، آن هنان كه در شكل ده مشاهده مى شود،

جدول r- توزيعهاى منطقهاى برگزيده بر اساس شاخص نكويى برازش Z، براى مناطق تشكيل شده بلوسيلهى SOFM و الكوريتم وارد در حالت دو منطقهاى

Table 2. Selected regional distributions based on the goodness-of-fit measure $\mathrm{Z}$ for the regions formed by SOFM and Ward's algorithm for 2-region state

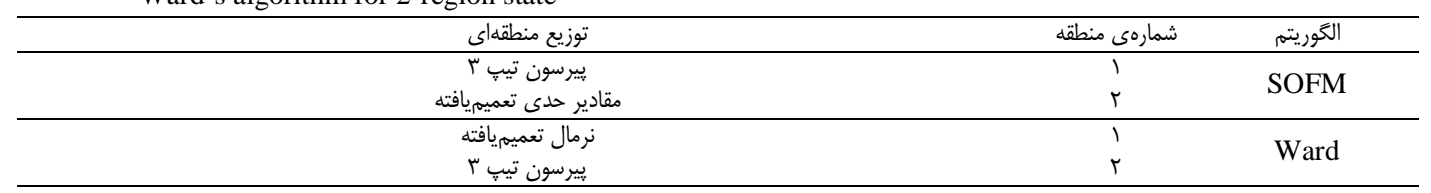




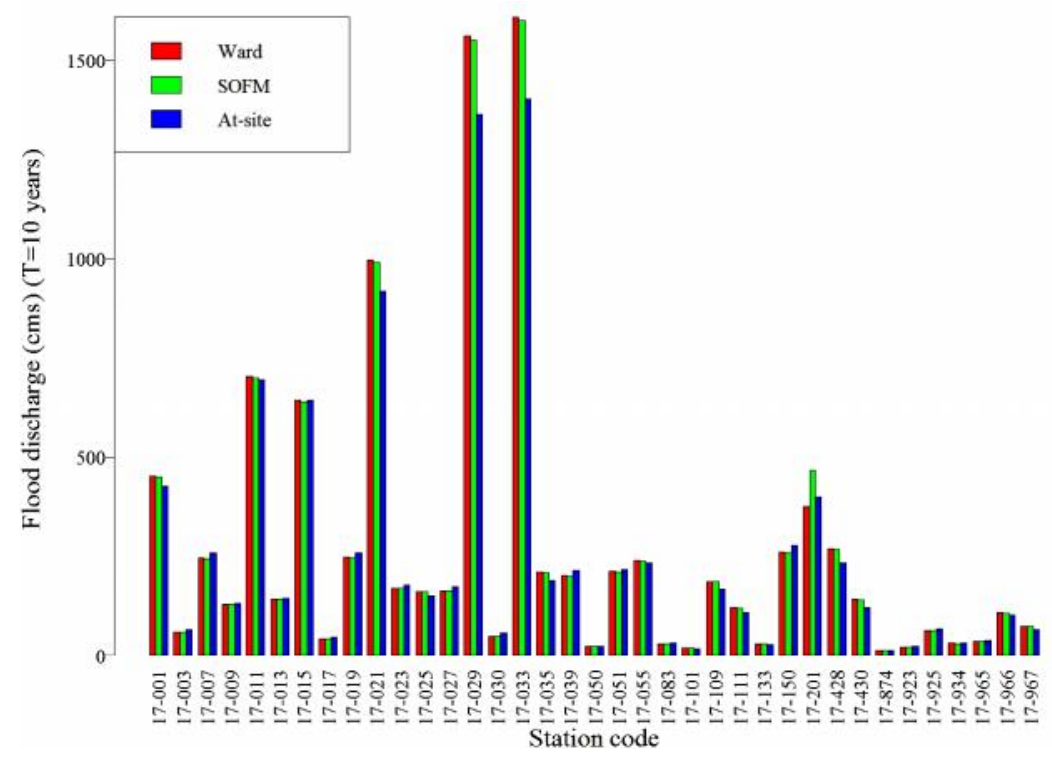

شكل • ا- برآورد سيلاب با دوره بازكشت ده سال با استفاده از تحليل فراوانى نقطهاى و تحليل فراوانى منطقاى بر اساس دو منطقهى

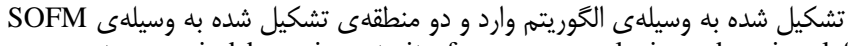

Figure 10. Flood estimates with ten-year return period by using at-site frequency analysis and regional frequency analysis based on two regions formed by Ward's algorithm and two regions formed by SOFM

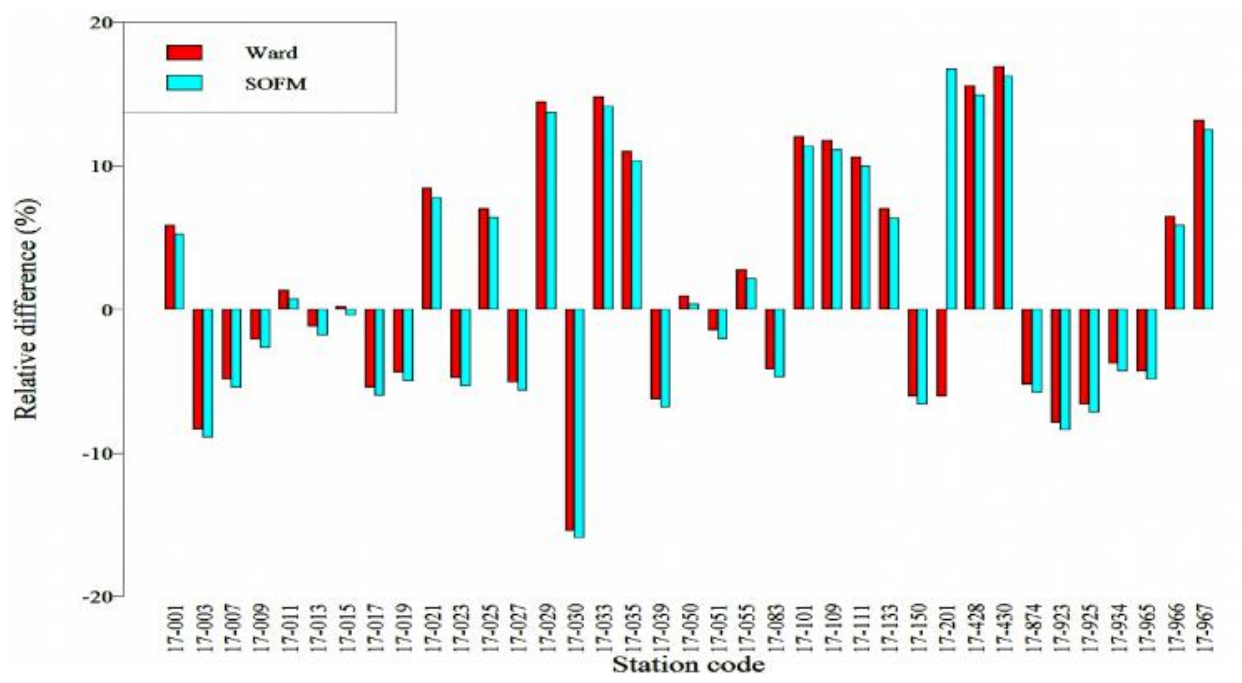

شكل II- مقايسهى برآوردهاى سيلاب با دوره باز گشت ده سال براى ايستخاههاى مورد مطالعه

Figure 11. Comparison of the flood estimates with ten-year return period for the interested stations

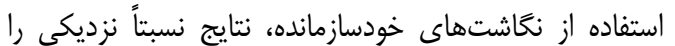

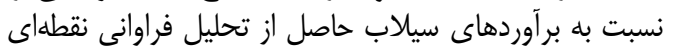

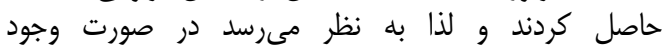

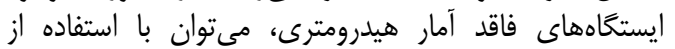

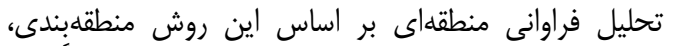

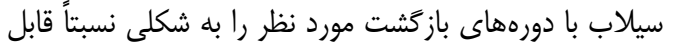

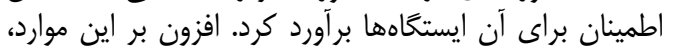

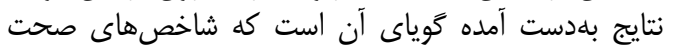

در نهايت بنا بر نتايج به دست آمده در اين مطالعه،

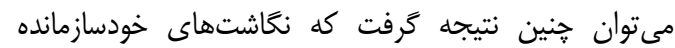

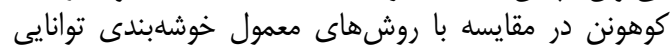

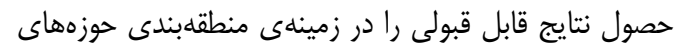

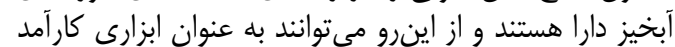

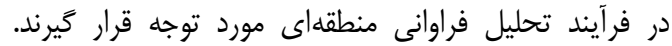

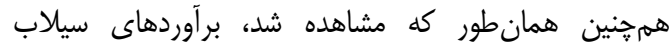
حاصل از تحليل فراوانى منطقهاى مبتنى بر منطقاهبندى با بال 


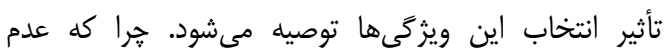

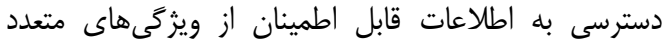

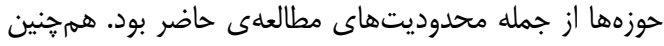

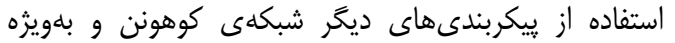

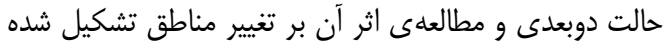

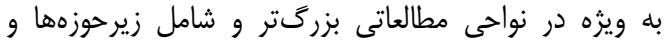

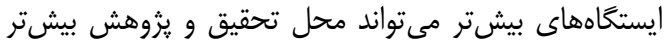

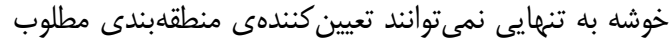

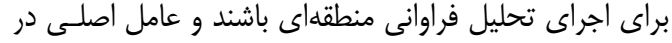

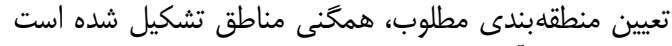

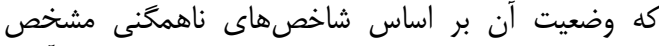

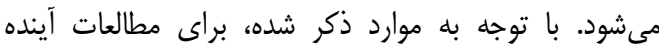

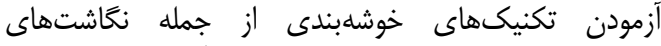

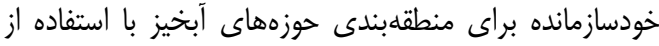

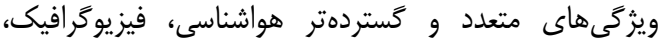

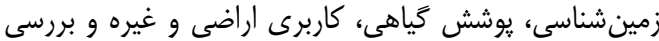

1. Ahani, A., S. Emamgholizadeh, S.S. Mousavi Nadoushani and K. Azhdari. 2015. Regional Flood Frequency Analysis by Hybrid Cluster Analysis and L-moments. Journal of Watershed Management Research, 6: 11-20.

2. Di Prinzio, M., A. Castellarin and E. Toth. 2011. Data-Driven Catchment Classification: Application to the Pub Problem. Hydrology and Earth System Sciences, 15: 1921-1935.

3. Hall, M.J. and A.W. Minns. 1998. Regional Flood Frequency Analysis Using Artificial Neural Network. In: Babovic, V. and L.C. Larsen (eds.), Proceedings of the Third International Conference on Hydro informatics (Copenhagen, Denmark), 2: 759-763.

4. Hall, M.J. and A.W. Minns. 1999. The Classification of Hydrologically Homogeneous Regions. Hydrological Sciences Journal, 44: 693-704.

5. Hall, M.J., A.W. Minns and A.K.M. Ashrafuzzaman. 2002. The Application of Data Mining Techniques for the Regionalization of Hydrological Variables. Hydrology and Earth System Sciences. 6: 685-694.

6. Haykin, S. 2009. Neural Networks: A Comprehensive Foundation. Pearson Education, Inc. 906 pp.

7. Hosking, J.R.M. and J.R. Wallis. 1997. Regional Frequency Analysis: An Approach Based on LMoments. Cambridge University Press, New York, USA. 224 pp.

8. Jingyi, Z. and M.J. Hall. 2004. Regional Flood Frequency Analysis for the Gan-Ming River Basin in China. Journal of Hydrology, 296: 98-117.

9. Kar, A.K., N.K. Goel, A.K. Lohani and G.P. Roy. 2012. Application of Clustering Techniques Using Prioritized Variables in Regional Flood Frequency Analysis - Case Study of Mahanadi Basin. Journal of Hydrologic Engineering- ASCE, 17: 213-223.

10. Kohonen, T. 1982. Self-Organized Formation of Topologically Correct Feature Maps. Biological Cybernetics, 43: 59-69.

11. Kohonen, T. 2001. Self-Organizing Maps. 3rd Extended Edn. Springer Verlag, Berlin, GERMANY, $501 \mathrm{pp}$.

12. Ley, R., M.C. Casper, H. Hellebrand and R. Merz. 2011. Catchment Classification by Runoff Behavior with Self-Organizing Maps (SOM). Hydrology and Earth System Sciences 15: 2947-2962.

13. Lin, G.F. and L.H. Chen. 2006. Identification of Homogeneous Regions for Regional Frequency Analysis Using the Self-Organizing Map. Journal of Hydrology, 324: 1-9.

14. Rao, A.R. and V.V. Srinivas. 2008. Regionalization of Watersheds-An Approach Based on Cluster Analysis, Series: Water Science and Technology Library, 248 pp.

15. Razavi, T. and P. Coulibaly. 2014. Classification of Ontario Watersheds Based on Physical Attributes and Streamflow Series. Journal of Hydrology, 493: 81-94.

16. Rousseeuw, P.J. 1987. Silhouettes: A graphical aid to the interpretation and validation of cluster analysis. Journal of Computational and Applied Mathematics, 20: 53-65.

17. Srinivas, V.V., S. Tripathi, A.R. Rao and R.S. Govindaraju. 2008. Regional Flood Frequency Analysis by Combining Self-Organizing Feature Map and Fuzzy Clustering. Journal of Hydrology, 348: 148-166.

18. Tabatabaei, M., K. Solaimani, M. Habibnejad Roshan and A. Kavian. 2014. Estimation of Daily Suspended Sediment Concentration using Estimation of Daily Suspended Sediment Concentration by Self-Organizing Map (Case Study: Sierra Hydrometry Station- Karaj Dam Watershed). Journal of Watershed Management Research, 5: 98-116.

19. Toth, E. 2013. Catchment Classification Based on Characterisation of Streamflow and Precipitation Time Series. Hydrology and Earth System Sciences, 17: 1149-1159.

20. Willshaw, D.J. and C. Von Der Malsburg. 1976. How Patterned Neural Connections Can be Set up by Self Organization. Proceedings of Royal Statistical Society London B, 194: 431-445. 


\title{
Regionalization of Watersheds Using a Type of ANNs to Regional Flood Frequency Analysis
}

\author{
Ali Ahani ${ }^{1}$, Samad Emamgholizadeh ${ }^{2}$, Seyyed Saeid Mousavi Nadoushani ${ }^{3}$ and \\ Khalil Azhdari $^{2}$

\begin{tabular}{c} 
Khali Azhdari \\
1- M.Sc. Student, Shahrood University of Technology, \\
(Corresponding author: ali.ahani66@ yahoo.com) \\
2- Associate Professor, Shahrood University of Technology \\
3- Assistant Professor, Shahid Beheshti University \\
Received: May 22, 2014 Accepted: October 14, 2015 \\
\hline \hline
\end{tabular}

\begin{abstract}
Self-Organizing Feature Maps (SOFM) are a variety of artificial neural networks that their applications in the areas of pattern recognition and data clustering makes them noticeable tools to perform regional flood frequency analysis (RFFA). In this study, ability of Self-Organizing Feature Maps for regionalization of Sefidrood watershed in order to perform regional flood frequency analysis using L-moment algorithm is assessed. Results of this study show that SOFMs may be used as an acceptable method for data clustering and regionalization of watersheds. Evaluation of values of cluster validity measures showed that they can't be a determining factor to identify suitable number of regions for regional flood frequency analysis, but homogeneity of regions is main factor to determine desirable number of regions. According to homogeneity of regions and sizes of formed regions, regionalizations including two regions that formed by Ward's algorithm and SOFM were chosen as optimum choices to regional flood frequency analysis on Sefidrood watershed. Furthermore, based on results of flood estimation by at-site FFA and two RFFA, regional estimates are very close to each other and their average relative difference is equal to $1 \%$ nearly. Also relative difference between regional and at-site estimates doesn't exceed $17 \%$ in any station and its mean value is about $8 \%$.
\end{abstract}

Keywords: Clustering, L-moments, Regionalization, SOFM 